\title{
The changing roles of neurons in the cortical subplate
}

\author{
Michael J. Friedlander ${ }^{1 *}$ and Juan Torres-Reveron ${ }^{2}$ \\ 1 Department of Neuroscience, Baylor College of Medicine, Houston, TX, USA \\ 2 Department of Neurosurgery, Yale University School of Medicine, New Haven, CT, USA
}

\section{Edited by:}

Kathleen S. Rockland, RIKEN Brain

Science Institute, Japan

\section{Reviewed by:}

Rick Lin, The University of Mississippi Medical Center, USA

Kathleen S. Rockland, RIKEN Brain

Science Institute, Japan

*Correspondence:

Michael J. Friedlander, Department of Neuroscience, Baylor College of

Medicine, Suite S740A, One Baylor

Plaza, Houston, TX 77030, USA.

e-mail: friedlan@bcm.edu
Neurons may serve different functions over the course of an organism's life. Recent evidence suggests that cortical subplate (SP) neurons including those that reside in the white matter may perform longitudinal multi-tasking at different stages of development. These cells play a key role in early cortical development in coordinating thalamocortical reciprocal innervation. At later stages of development, they become integrated within the cortical microcircuitry. This type of longitudinal multi-tasking can enhance the capacity for information processing by populations of cells serving different functions over the lifespan. Subplate cells are initially derived when cells from the ventricular zone underlying the cortex migrate to the cortical preplate that is subsequently split by the differentiating neurons of the cortical plate with some neurons locating in the marginal zone and others settling below in the SP. While the cortical plate neurons form most of the cortical layers (layers 2-6), the marginal zone neurons form layer 1 and the SP neurons become interstitial cells of the white matter as well as forming a compact sublayer along the bottom of layer 6 . After serving as transient innervation targets for thalamocortical axons, most of these cells die and layer 4 neurons become innervated by thalamic axons. However, $10-20 \%$ survives, remaining into adulthood along the bottom of layer 6 and as a scattered population of interstitial neurons in the white matter. Surviving SP cells' axons project throughout the overlying laminae, reaching layer 1 and issuing axon collaterals within white matter and in lower layer 6 . This suggests that they participate in local synaptic networks, as well. Moreover, they receive excitatory and inhibitory synaptic inputs, potentially monitoring outputs from axon collaterals of cortical efferents, from cortical afferents and/or from each other. We explore our understanding of the functional connectivity of these cells at different stages of development.

Keywords: subplate, white matter, cortex, subgriseal, longitudinal multi-tasking

\section{PROPOSAL OF RE-SPECIFICATION OF NEURONAL PROPERTIES DURING DEVELOPMENT}

We propose that certain types of neurons can undergo a temporal re-specification of function over the lifespan. Specifically, we suggest that the population of cortical subplate (SP) neurons does so although it is not known whether individual neurons in that cohort of cells change their function or if the surviving SP cells represent a sub-population that has different functions at different stages of the life cycle. Although we propose a long term type of multi-tasking over the lifespan, there may be other types of neuronal multi-tasking operating over shorter time scales. For example, within minutes, as information is being processed, neuromodulators and recent bouts of activity could unmask emergent functional properties such as regulation of gene expression leading to differential functions of individual neurons within the neuronal circuit within which the cell is embedded. Recording of electrical activity from large populations of interacting neurons will be required while following individual neurons' activity profiles for extended periods with tetrode arrays (Schmitzer-Torbert et al., 2005) to directly test these ideas. Current technology can apply in vivo optical monitoring of the dynamics of the structure of dendrites, spines and axons although this approach is generally limited to superficial cortical layers (Kerr et al., 2007). New advances in imaging technology will be required for similar tracking of deep cells such as SP neurons during development. It will also be of interest to evaluate whether changes in neuronal function occur over the course of aging. For example, the neocortex shrinks during normal aging due primarily to atrophy of cells and the neuropile (vs. neuronal loss - Freeman et al., 2008). Future studies of individual cellular and neuronal network function during aging may reveal other examples of serial neuronal multi-tasking.

Differential expression of genes plays a major role in neuronal development and functional differentiation not only from early embryonic stages (Hevner, 2006; Mallamaci and Stoykova, 2006; Mehler and Mattick, 2007; Taniura et al., 2007; Webster et al., 2006; Zimmermann, 2006) but also into senescence (Burger et al., 2007; Chu et al., 2002; Liu et al., 2009). These changes can be programmed to occur at defined stages or can be triggered by local signals, by environmental inputs or in a neuronal activity-regulated manner. Such temporally modulated regulation of gene expression can play a role in target recognition and path-finding, synaptogenesis, refinement of synaptic connections (Waites et al., 2005) as well as in cell death (Jansen et al., 2007; Lindsten et al., 2005). In addition, other influences such as sensory or motor activity, cognition, stress, infectious agents and traumatic events can alter gene expression patterns in the brain throughout life (Alfonso et al., 2005; Licino et al., 2007; McClung and Nestler, 2008). 
However, after differentiation to a particular phenotype, little change is thought to occur in each neuron's fundamental properties such as their anatomical projections, location, position, chemical neurotransmitter, and the functions of the cell within the framework of the particular network where it resides. For example, a glutamatergic cortico-thalamic neuron that projects from layer 6 of the primary visual cortex to the dorsal lateral geniculate nucleus may alter composition and properties of its ion channels and neurotransmitter receptor subunits over the course of development but remain essentially the same cell "type" - an excitatory feedback visual relay pyramidal neuron processing visual information with particular receptive field properties that innervates the LGN and cortical layer 4.

\section{EARLY ROLE OF SUBPLATE NEURONS IN CORTICAL DEVELOPMENT}

Pleiotropy (the ability of a single gene to influence multiple phenotypic traits) is well established (Fraser and Marcotte, 2004). Neurons can express pleiotropic genes or respond to pleiotropic gene products at different times throughout an organism's life, potentially increasing information processing ability longitudinally and responding to stimuli and stressors (de Magalhães and Sandberg, 2005; Louvi et al., 2004; Nelson et al., 2006; Russo et al., 2005). Like genes, whole neurons could increase their information processing contribution combinatorially by serving different functions over the course of the lifespan - a pleiotropy of cellular function in the temporal domain. The neurons of the cortical SP are one candidate population of cells that may behave in this manner. The SP cells emerge from the ventricular zone under the cerebral cortex, migrating below the marginal zone to the cortical preplate (Stewart and Pearlman, 1987) that is then split by the differentiating neurons of the cortical plate - some neurons taking up residence in the marginal zone and others settling below the cortical plate in the SP (König et al., 1981; Luskin and Shatz, 1985a,b; Marin-Padilla, 1971, 1978). The cortical plate neurons form most of the cortical layers (layers 2-6) while the marginal zone neurons become layer 1 and the SP neurons become interstitial cell of the cortical white matter as well as clustering at the bottom of the cortical plate just below layer 6 (layer 6b - DeDiego et al., 1994; Marin-Padilla and Marin-Padilla, 1982; Valverde et al., 1989; Woo et al., 1991). These SP cells are among the first cortical neurons to differentiate into a neuronal phenotype; they express microtubule associated protein-2 and neuropeptides before the cortical plate neurons (Arias et al., 2002; Clancy et al., 2001; Finney et al., 1998; Luskin and Shatz, 1985), they receive synaptic inputs and generate action potentials through embryonic development (Hanganu et al., 2001; Kanold, 2004; Kanold et al., 2003). These cells also serve as pioneers issuing axons into the internal capsule where they serve an important role by innervating the thalamus and providing a scaffold for the innervation of the cortex by the thalamocortical axons (Allendoerfer and Shatz, 1994; Friauf et al., 1990; Ghosh et al., 1990; Herrmann et al., 1994; Kanold et al., 2003; McConnell et al., 1989). The SP neurons are also transiently innervated by the in growing thalamocortical axons before the eventual thalamocortical target neurons within cortical layer 4 settle in their ultimate positions in the cortical plate to receive their innervation. Layer 4 neurons receive innervation by both SP neurons and thalamic axons during this period (Kanold, 2004; Kanold et al., 2003) followed by removal of inputs from the SP cells through a competitive process (Friauf et al., 1990; Kanold et al., 2003). If the SP cells are lesioned, the thalamic axons fail to innervate their correct target areas (Chun and Shatz, 1989; McConnell et al., 1989, 1994) and cortical columnar organization does not develop normally (Kanold et al., 2003). Thus, these neurons contribute to establishing functional cortical architecture during development. After performing those functions, most of these cells die (Al-Ghoul and Miller, 1989; Chun and Shatz, 1989; Wood et al., 1992).

\section{SURVIVING SUBPLATE NEURONS}

The SP neurons appear to play an important but fleeting role in orchestrating early cortical development. However, although most of these cells die soon after the innervation of the cortical plate by thalamic axons and the retraction of the SP neurons' axons that innervate layer 4, many of them (10-20\%) survive (Chun and Shatz, 1989; Torres-Reveron and Friedlander, 2007). These cells remain throughout development into adulthood as a compressed band along the bottom of layer 6 (cortical layer $6 \mathrm{~b}$ or cortical layer 7 or subgriseal cells - Valverde et al., 1989; Vandevelde et al., 1996; Reep and Goodwin, 1988; Clancy and Caullier, 1999) and as dispersed interstitial neurons scattered in the white matter. It is a matter of considerable interest to know the fate of this group of surviving cells - are they quiescent, do they serve a role in guidance in the postnatal brain as they did prenatally or do they take on an entirely new function? If they change their function and/or connectivity, this suggests a form of temporal pleiotropy for these cells. As these SP cells are greatly reduced in number during development, it is possible that they serve no major functional role after this period. However, this seems unlikely and there are other examples of numerically small neuronal types that contribute in important ways through processes such as numerical expansion of target innervation by axonal and synaptic divergence (retinogeniculocortical Y-cells - Friedlander and Martin, 1989; Friedlander et al., 1985); strategically positioned or particularly strong synaptic outputs (climbing fibers - Shinoda et al., 2000); or potent neuromodulatory outputs (Landgraf and Neumann, 2004; Rygh et al., 2006). Thus, the fact that many of these cells are lost during development should not exclude the possibility that the remaining population of these cells, although relatively small in sheer number may play some additional important role in cortical information processing. In order to evaluate such a hypothesis, it is necessary to directly evaluate the anatomical and electrophysiological properties of this reduced cohort after their initial role in cortical development and after the elimination of the majority of cells have occurred.

Figure 1 illustrates an example of a surviving white matter neuron located below the primary visual cortex of a postnatal day 20 rat that has been patched in a brain slice preparation with a biocytin filled micropipette and subsequently processed for biocytin and stained with cresyl violet.

Note that the cell's dendrites are oriented along the white matter below layer 6 . An example of a surviving SP neuron located along the bottom of layer 6 that was also patched in a brain slice preparation and filled with biocytin is shown in Figure 2. The inset illustrates that the cell responds to a sustained direct depolarizing input with a non-decrementing train of action potentials similar to cortical interneurons. 


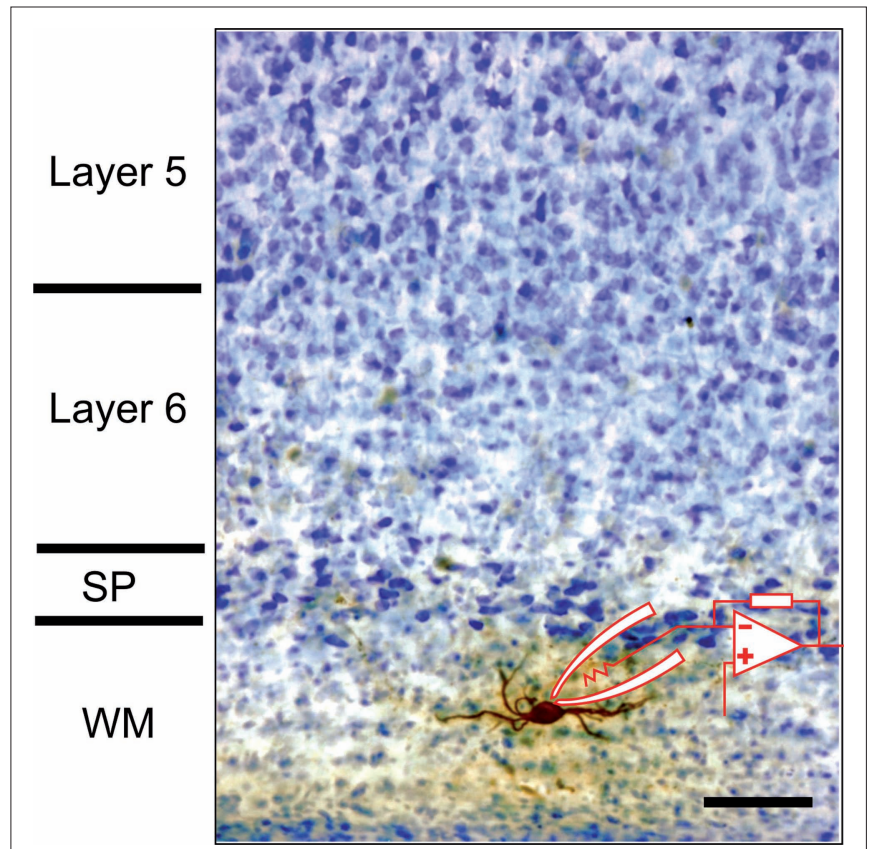

FIGURE 1 | Photomicrograph of biocytin filled white matter neuron in slice preparation from rat visual cortex. Patch pipette and recording arrangement are schematized. Tissue was counter-stained with cresyl violet after biocytin processing. Scale bar $=50 \mu \mathrm{m}$.

\section{MORPHOLOGY AND NITRIC OXIDE SYNTHASE}

SP cells have been shown to be particularly susceptible to or play a role in the pathogenesis of disorders including early neonatal hypoxic-ischemic injury (McQuillen et al., 2003), trisomies (Cheng et al., 2004), microcephaly (Takano et al., 2006) and seizures (Kadam and Dudek, 2007). Although their potential role in such diseases has been studied, there are few studies of the functional properties of the surviving SP neuronal population in the normal brain likely due to their sparseness and location, making such studies difficult. These surviving cells express markers typical of neurons including MAP-2 and NeuN (Clancy et al., 2001; Torres-Reveron and Friedlander, 2007) and many express the synthetic enzyme for the production of nitric oxide (NO), nitric oxide synthase (NOS) that can be visualized as NADPH diaphorase (NADPHd) activity. This is illustrated in Figure 3 where white matter neurons from human (Figures 3A,B) and rat brain (Figures 3C,D) that are positive for NADPHd are shown in tissue from young and mature brains. Human cortical tissue was obtained from resections from patients for treatment of epilepsy at the University of Alabama at Birmingham Hospital under an IRB protocol for utilization of waste tissue for histological processing and electrophysiology.

Note that not only the somata and dendrites are positive for NADPHd but that there is also considerable staining of fine processes and varicosities, suggesting the possibility that these cells may provide a diffusible signal $(\mathrm{NO})$ in the white matter that could play a role in plasticity and/or pathogenesis (Garthwaite, 2008).

Retrogradely transported tracers applied to the surface of the cortex (layer 1) backfill surviving WM and SP neurons' somata, indicating that their axons reach the cortical surface (Clancy and Caullier, 1999). This projection as well as the presence of boutons

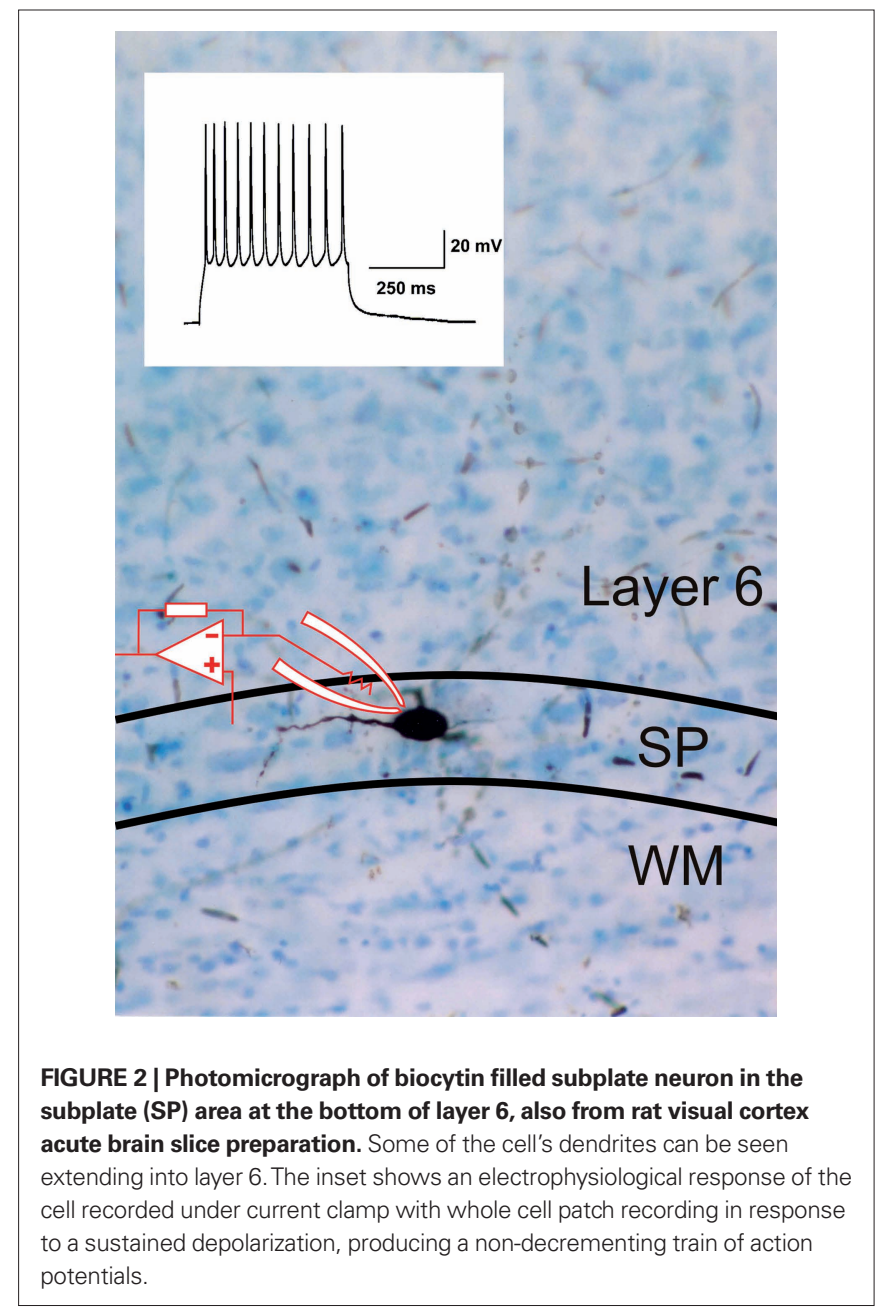

on their axons in other cortical layers have been demonstrated for individual surviving white matter and SP neurons where their axonal arborizations are visualized by intracellular single cell filling (Clancy et al., 2001). An example of a SP neuron whose axon projects upward through the visual cortical layers is illustrated in Figure 4. Although SP and WM cells are not numerous, their axonal arborizations can be expansive, covering span up to a millimeter of cortex in the medio-lateral axis (Clancy et al., 2001). These neurons also issue axon collaterals within the white matter and deep layer 6, providing the neuroanatomical substrate for them to play a role in a local functional neuronal network.

\section{FUNCTIONAL PROPERTIES, CONNECTIVITY AND NEUROMODULATORY PHENOTYPES}

Surviving SP neurons generate action potentials; they receive both excitatory and inhibitory synaptic inputs; and they respond to sustained membrane depolarization with minimal spike frequency adaptation (Torres-Reveron and Friedlander, 2007). Thus, these cells retain a neuronal phenotype, they receive synaptic inputs from other neurons and they innervate the various cortical layers. We have also recently found (Torres-Reveron and Friedlander, 2005) that these cells provide glutamatergic excitatory synaptic inputs to neurons in cortical layer 6. An example is illustrated (Figure 5A) as recordings 

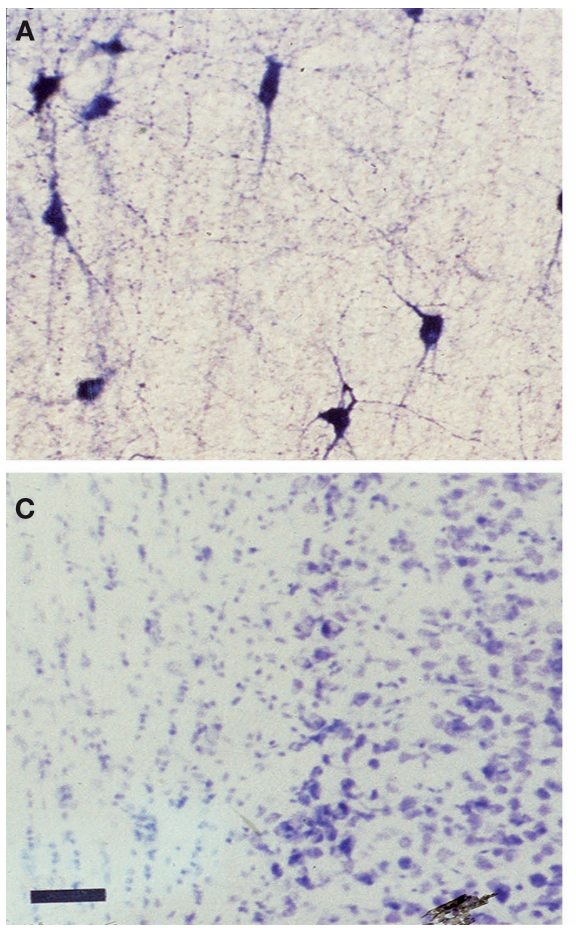

FIGURE 3 | NOS positive neurons in WM and SP. (A,B) Photomicrographs of white matter and subplate area in visual cortex from tissue obtained from human brain (after tissue resection for epilepsy surgery) from a young (3 years of age) and an older ( 40 years of age) subject and (C,D) from adult rat (42 days postnatal) visual cortex where tissue has been processed for NADPH diaphorase histochemistry. All photomicrographs are oriented with the cortical surface to the right. The human tissue shows numerous white matter neurons that are
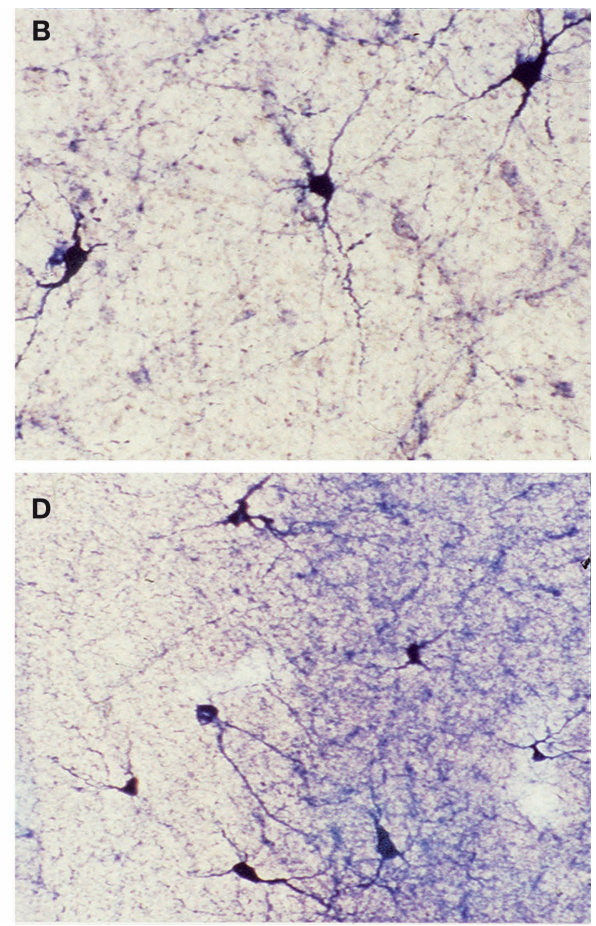

NADPHd positive in the white matter and considerable staining of processes, as well. The rat tissue sections illustrate a standard Nissl stain (C) where the subplate neurons can be visualized as a compressed layer at the bottom of layer 6 and the white matter is seen below. The section in (D) (an adjacent section) has been processed for NADPHd histochemistry - several NADPHd positive neurons can be seen in the white matter and in the subplate subgriseal area at the bottom of layer 6 . Scale bar $=50 \mu \mathrm{m}$ and applies to all four panels.

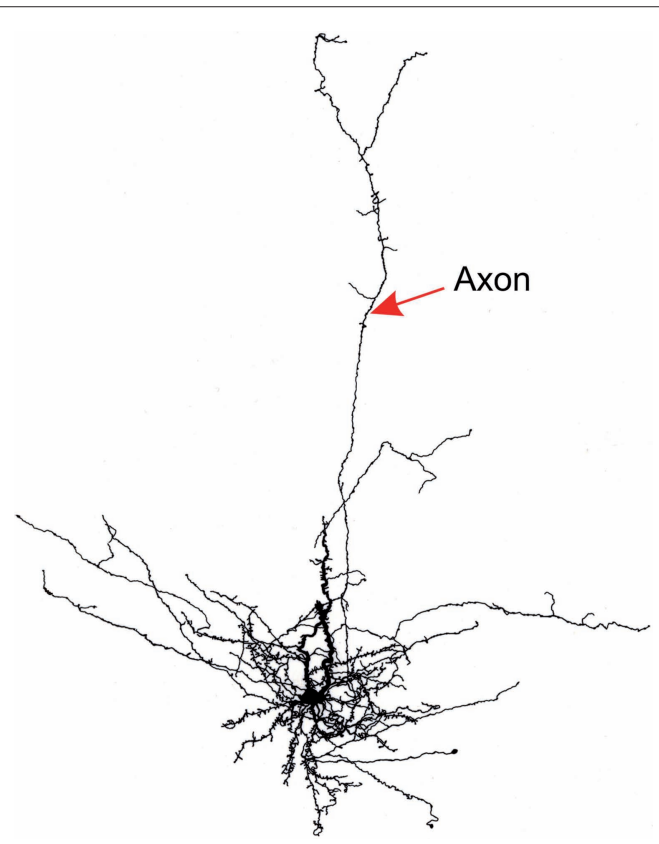

FIGURE 4 | Line drawing of a rat subplate neuron that has been filled with biocytin in a brain slice experiment. The cell's dendrites cluster around the soma at the base of layer 6 but its axon extends vertically into the cortical plate. from a pair of synaptically connected SP - layer 6 cells recorded in dual whole cell patch clamp mode. In this case, a SP neuron at the bottom of layer 6 was patched and individual spikes were elicited every $10 \mathrm{~s}$ while several putative postsynaptic neurons in layer 5 and layer 6 were also patched and tested for the presence of evoked unitary postsynaptic responses. The layer 6 neuron responded with small unitary EPSPs (EPSPs evoked from a single action potential in a single presynaptic neuron) that can be seen in individual trails and as an averaged response in Figure 5B. Thus, surviving SP neurons not only are positioned to receive inputs from either axon collaterals of supraor infragranular cortical projection neurons, from cortical afferents and from each other but some of them also provide excitatory synaptic input to the overlying cortical plate neurons. Interestingly, GABAergic white matter neurons with projection axons have been identified in primates (Tomioka and Rockland, 2007) and we have seen a subset of GABAergic WM and SP neurons in rat using immunohistochemistry, although we have yet to record from an identified surviving presynaptic GABAergic neuron. In addition to having fast glutamatergic excitatory synaptic output, these cells also stain positively for various neuromodulators including substance P,CCK, somatostatin and NOS. Sections that have been immuno-stained for these various substances are illustrated in Figure 6. The diversity of secreted chemical that these surviving cells contain together with their capacity to maintain protracted non-decrementing trains of action potentials in response to a sustained depolarizing drive may afford these surviving neurons 


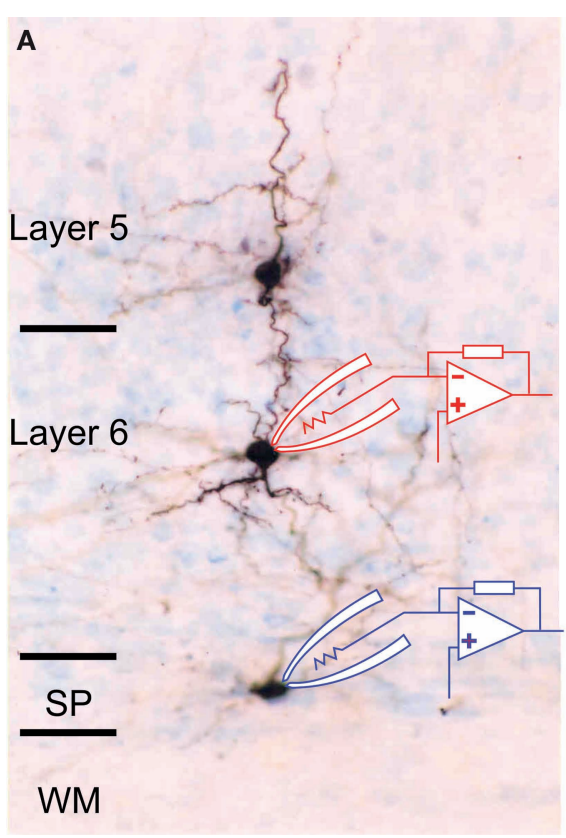

\section{B}

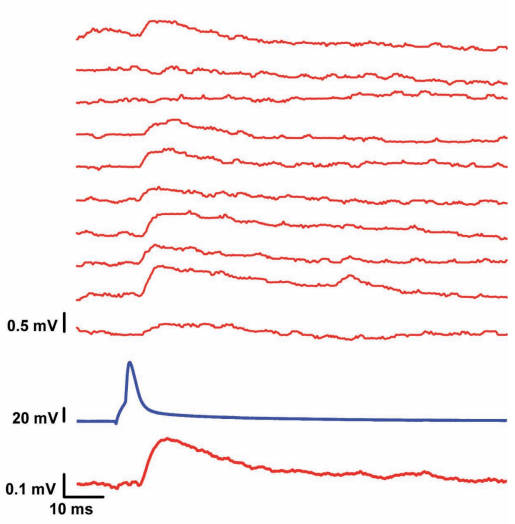

FIGURE 5 | Functional synaptic connections between SP and layer 6 neurons. (A) Photomicrograph of the brain slice preparation where three cells were patched, recorded and tested for synaptic interactions. The lower cell located in the subgriseal area (SG) of the subplate at the bottom of layer 6 functionally innervated the layer 6 neuron above it (but not the layer 5 neuron above that). (B) The functional synaptic connection was ascertained through dual whole cell patch clamp electrophysiological recording where a single action

potential was evoked every $10 \mathrm{~s}$ in the subplate neuron (trace second from bottom) while the evoked unitary synaptic responses were recorded under current clamp conditions from the layer 6 cell (10 individual trials shown in top traces). Note that on some trials, there was no detectable response (an apparent transmission failure) while in most trials, a small depolarizing postsynaptic response was evoked. The resting membrane potential of the layer 6 neuron was $-70 \mathrm{mV}$.

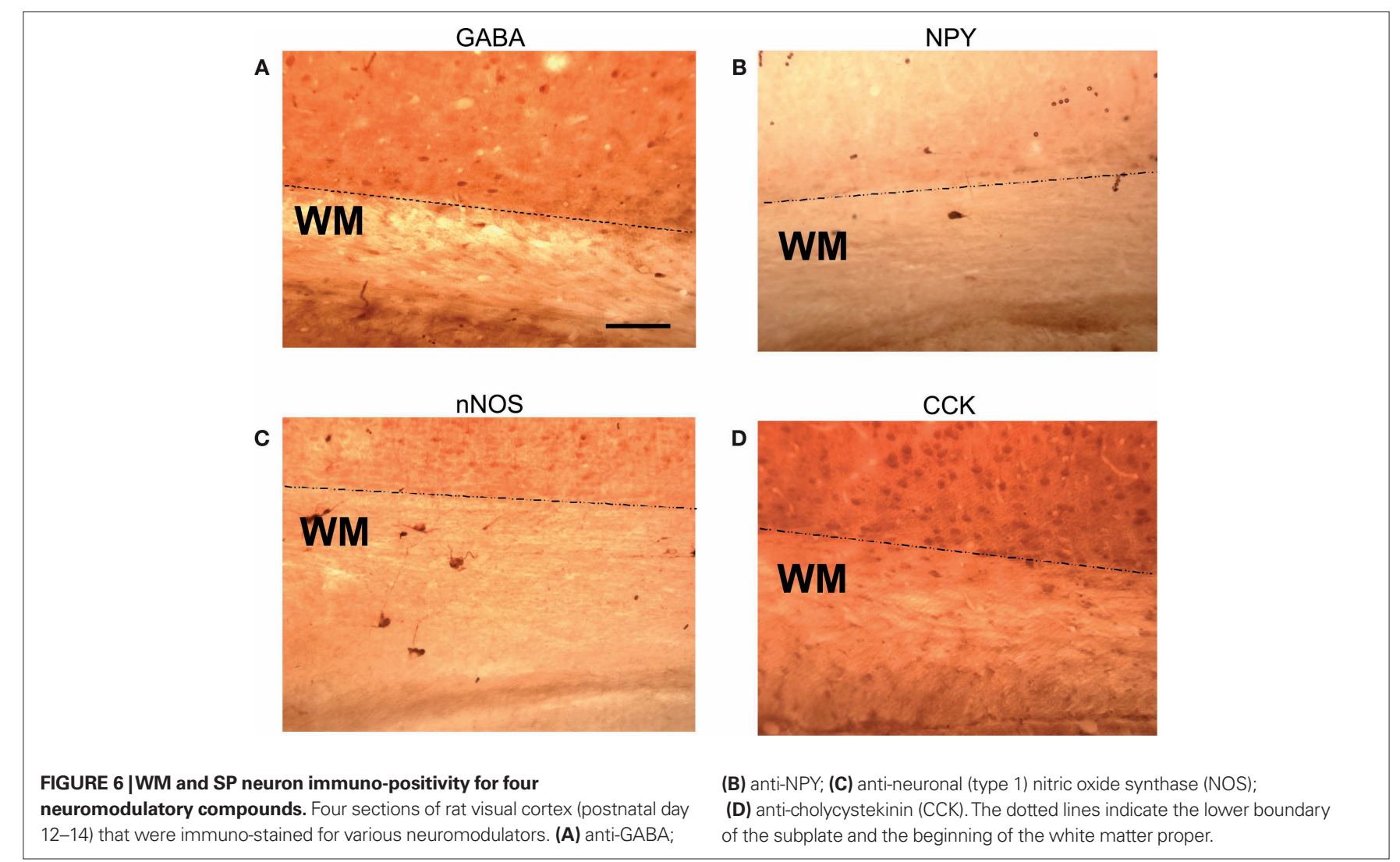


the capacity to provide strong neuromodulatory effects to cells in the overlying cortex.

\section{POTENTIAL ROLE FOR SP NEURONS FOR INFORMATION PROCESSING IN THE MATURE CORTEX}

That these cells remain as neurons but also have the capacity to play different roles at different stages of development is suggested by several factors. These include the persistence of intrinsic electrophysiological and synaptic properties, survival of the glutamatergic phenotype, receipt of excitatory and inhibitory synaptic inputs from other sources after the loss of their thalamocortical inputs and the re-arrangement of their axonal outputs from transiently innervating layer 4 to innervating all cortical layers. Much of the information about the properties of these surviving cells must, by necessity be obtained from in vitro brain slice preparations so there is little known about their properties within the circuitry of the intact brain. While their basic electrophysiological properties can be studied in the brain slice preparation, features such as how they process sensory information or identifying the sources of their synaptic inputs from distant sites are difficult to determine in vivo since the cells are sparse (WM interstitial cells) or compressed in a thin sheet (the SP cells at the bottom of layer 6 or subgriseal cells). Thus, although we now know somewhat more about the intrinsic and local synaptic properties of these cells in the postnatal brain, there precise function within the mature cortical network must remain somewhat speculative.

The surviving group of SP neurons may function as a sort of cortical gatekeeper, modulating information flow into and out of modules of overlying cortex to other cortical sites. Neurons of the nucleus reticularis thalami (NRT) proximal to thalamic nuclei carry out a similar function as a scattered cohort of GABAergic neurons that are embedded within the internal capsule and receive collateral excitatory innervation from thalamocortical axons as well as from cortico-thalamic axons and provide connectivity to each other within the NRT (Bokor et al., 2005; Gentet and Ulrich, 2004). They innervate thalamic neurons in inhibitory feedback projection from the thalamus and provide an inhibitory feed-forward projection from layer 6 of the cortex, as well. The NRT cells can modify the information processing state and the relay of information from the sensory periphery to the cortex by modulating membrane potential (Kim and McCormick, 1998; Ulrich and Huguenard, 1996). The cohort of surviving white matter and SP neurons may perform a related function in the cortex.

The dendritic arborizations of the WM and SP neurons within cortical layer 6 position them strategically to receive synaptic input that is otherwise destined for layer 4 from collaterals of thalamocortical axons that also arborize in layer 6 (Binzegger et al., 2005; Douglas and Martin, 2004; Molinari et al., 1995). In addition, they could also receive synaptic input from cortical layer 2 and 3 cells' axons that send axon collaterals to layer 6 (Douglas and Martin, 2004; Martin, 2002) and even into the white matter so that these neurons could also receive a copy of information that has been processed within the cortical columnar structure and is being relayed to other cortical areas. Although their somata are located within the white matter, many of the interstitial white matter neurons also have dendrites located in layer 6 where they are also positioned to potentially receive similar synaptic inputs. A difference between these neurons and the NRT cells is that most of the surviving SP and many white matter neurons are glutamatergic vs. GABAergic. However, it is interesting to note that a substantial fraction of the SP neurons are GABAergic, although we apparently have only recorded from the glutamatergic ones in our paired recordings since in all cases, the postsynaptic response was excitatory. It is not clear why our recordings should select only the glutamatergic neurons in the SP but because our results are so far limited to that sub-population, the multi-tasking behavior of these cells might be limited to certain subsets. The excitatory synaptic output of the SP and WM neurons to the cortical layers above could provide either feed-forward (for the thalamocortical inputs) and/or feedback (for the cortical efferents) information. Since the surviving SP neurons are mostly excitatory and they innervate neighboring SP cells in addition to the overlying cortical neurons, they could act as an amplification network for important signals through activating of a local network of neighboring like-type cells as well as a subset of postsynaptic targets in the overlying cortex. Recurrent excitation in such an arrangement could however, create network instability or seizures (Scharfman, 2007; Winokur et al., 2004) but depending on the types of cells that are targeted (e.g. glutamatergic excitatory vs. GABAergic inhibitory neurons), the properties of such a circuit may allow for selective amplification and contrast enhancement through feedback inhibition. The neuromodulatory chemicals in the SP and WM neurons such as NOS (Clancy et al., 2001) and various neuropeptides such as substance P (Chun and Shatz, 1989; Chun et al., 1987; Uylings and Delalle, 1997) further enhance the potential of these cells' output functions through signal gating or selective amplification that could be useful for attention, sensory learning by enhancing signal to noise ratios or changing activation thresholds and synaptic integration properties of neurons within the cortical network.

\section{SUMMARY}

There still remain considerable issues to be resolved regarding the role of these intriguing SP neurons within the mature neocortex. For example, how do the surviving cells avoid elimination during development? Which cells provide the synaptic inputs to these neurons? What are the functional properties of these neurons in vivo? What role do the many neuromodulators released by these cells play in information processing? Do these surviving white matter and SP neurons retain the capacity to re-enable early developmental processes in the adult cortex after injury or disease? The answers to many of these questions must await experiments where these cells are studied in the adult brain in vivo with selective targeting techniques. However, it is clear that $\mathrm{SP}$ neurons perform important functions in the cortex during early development and that a substantial number of these cells organizes into a different functional network in the postnatal brain that could contribute to cortical function in other ways. Whether such longitudinal pleiotropy of neuronal phenotype applies throughout the lifespan to the aging brain and/or to other neuronal populations remains to be evaluated. If so, this would dramatically enhance the capacity of neuronal networks throughout the lifespan.

\section{ACKNOWLEDGEMENTS}

This work was supported by NIH grants EY 12782 and HD-38760 to MJF and F31 NS 10608 to JTR. We thank Felecia Hester and Susanna Kiss for technical assistance and Iskander Ismailov for help with the figures. 


\section{REFERENCES}

Alfonso, J., Frasch, A. C., and Flugge, G. (2005). Chronic stress, depression and antidepressants: effects on gene transcription in the hippocampus. Rev. Neurosci. 16, 43-56.

Al-Ghoul, W. M., and Miller, M. W. (1989). Transient expression of Alz-50 immunoreactivity in developing rat neocortex: a marker for naturally occurring neuronal death? Brain Res. 481, 361-367.

Allendoerfer, K. L., and Shatz, C. J. (1994). The subplate, a transient neocortical structure: its role in the development of connections between thalamus and cortex. Annu. Rev. Neurosci. 17, 185-218.

Arias, M. S., Baratta, J., Yu, J., and Robertson, R.T. (2002). Absence of selectivity in the loss of neurons from the developing cortical subplate of the rat. Brain Res. Dev. Brain Res. 139, 331-335.

Binzegger, T., Douglas, R. J., and Martin, K. A. (2005). Axons in the cat visual cortex are topologically selfsimilar. Cereb. Cortex 15, 152-165.

Bokor, H., Frère, S. G., Eyre, M. D., Slezia, A., Ulbert, I., Luthi, A., and Acsady, L. (2005). Selective GABAergic control of higher-order thalamic relays. Neuron 45, 929-940.

Burger, C., López, M. C., Feller, J. A., Baker, H. V., Muzyczka, N., and Mandel, R. J. (2007). Changes in transcription within the CAl field of the hippocampus are associated with age-related spatial learning impairments. Neurobiol. Learn. Mem. 87, 21-41.

Cheng, A., Haydar, T. F., Yarowsky, P. J., and Krueger, B. K. (2004). Concurrent generation of subplate and cortical plate neurons in developing trisomy 16 mouse cortex. Dev. Neurosci. 26 255-265.

Chu, Y., Kompoliti, K., Cochran, E. J., Mufson, E. J., and Kordower, J. H. (2002). Age-related decreases in Nurr1 immunoreactivity in the human substantia nigra. J. Comp. Neurol. 450, 203-214.

Chun, J.J., Nakamura, M. J., and Shatz, C. J. (1987). Transient cells of the developing mammalian telencephalon are peptide-immunoreactive neurons. Nature 325, 617-620.

Chun, J. J., and Shatz, C. J. (1989). Interstitial cells of the adult neocortical white matter are the remnant of the early generated subplate neuronal population. J. Comp. Neurol. 282, 555-569.

Clancy, B., and Caullier, I. J. (1999). Widespread projections from subgriseal neurons (layer VII) to layer I in adult rat cortex. J. Comp. Neurol. 407, 275-286.
Clancy, B., Silva-Filho, M., and Friedlander, M. J. (2001). Structure and projections of white matter neurons in the postnatal rat visual cortex. J. Comp. Neurol. 434, 233-252.

DeDiego, I., Smith-Fernández, A., and Fairén, A. (1994). Cortical cells that migrate beyond area boundaries: characterization of an early neuronal population in the lower intermediate zone of prenatal rats. Eur. J. Neurosci. 6, 983-997.

de Magalhães, J. P., and Sandberg, A. (2005). Cognitive aging as an extension of brain development: a model linking learning, brain plasticity, and neurodegeneration. Mech. Ageing Dev. 126, 1026-1033.

Douglas, R. J., and Martin, K. A. (2004) Neuronal circuits of the neocortex. Annu. Rev. Neurosci. 27, 419-451.

Finney, E. M., Stone, J. R., and Shatz, C. J. (1998). Major glutamatergic projection from subplate into visual cortex during development. J. Comp. Neurol. 398, 105-118.

Fraser, A. G., and Marcotte, E. M. (2004). A probabilistic view of gene function. Nat. Genet. 36, 559-564.

Freeman, S. H., Kandel, R., Cruz, L., Rozkalne, A., Newell, K., Frosch, M. P., Hedley-Whyte, E. T., Locasio, J. J., Lipsitz, L. A., and Hyman B. T. (2008). Preservation of neuronal number despite age-related cortical brain atrophy in elderly subjects without Alzheimer's disease. J. Neuropathol. Exp. Neurol. 67, 1205-1212.

Friauf, E., McConnell, S. K., and Shatz, C. J. (1990). Functional synaptic circuits in the subplate during fetal and early postnatal development of cat visual cortex. J. Neurosci. 10, 2601-2613.

Friedlander, M. J., and Martin, K. A. (1989). Development of Y-axon innervation of cortical area 18 in the cat. J. Physiol. 416, 183-213.

Friedlander, M. J., Martin, K. A., and Vahle-Hinz, C. (1985). The structure of the terminal arborizations of physiologically identified retinal ganglion cell $\mathrm{Y}$ axons in the kitten. J. Physiol. 359, 293-313.

Garthwaite, J. (2008). Concepts of neural nitric oxide mediated transmission. Eur. J. Neurosci. 27, 2783-2802.

Gentet, L. J., and Ulrich, D. (2004). Electrophysiological characterization of synaptic connections between layer VI cortical cells and neurons of the nucleus reticularis thalami in juvenile rats. Eur. J. Neurosci. 19 625-633.

Ghosh, A., Antonini, A., McConnell, S. K., and Shatz, C. J. (1990). Requirement for subplate neurons in the formation of thalamocortical connections. Nature 347, 179-181.
Hanganu, I.L., Kilb, W., and Luhmann H. J. (2001). Functional synaptic projections onto subplate neurons in neonatal rat somatosensory cortex. J. Neurosci. 22, 7165-7176.

Herrmann, K., Antonini, A., and Shatz, C. J. (1994). Ultrastructural evidence for synaptic interactions between thalamocortical axons and subplate neurons. Eur. J. Neurosci. 6 , 1729-1742.

Hevner, R. F. (2006). From radial glia to pyramidal-projection neuron: transcription factor cascades in cerebral cortex development. Mol. Neurobiol. 33, 33-50.

Jansen, P., Giehl, K., Nyengaard, J. R. Teng, K., Lioubinski, O. Sjoegaard, S. S., Breidhoff, T., Gotthardt, M., Lin, F., Eilers, A. Petersen, C. M., Lewin, G. R. Hempstead, B. L., Willnow, T. E., and Nykjaer, A. (2007). Roles for the proneurotrophin receptor sortilin in neuronal development, aging and brain injury. Nat. Neurosci. 10, 1449-1457.

Kadam, S. D., and Dudek, F. E. (2007). Neuropathogical features of a rat model for perinatal hypoxic-ischemic encephalopathy with associated epilepsy. J. Comp. Neurol. 505, 716-737.

Kanold, P. O. (2004). Transient microcircuits formed by subplate neurons and their role in functional development of thalamocortical connections. Neuroreport 15, 2149-2153.

Kanold, P. O., Kara, P., Reid, R. C., and Shatz, C. J. (2003). Role of subplate neurons in functional maturation of cortical columns. Science 301, 521-525.

Kerr, J. N., de Kock, C. P., Greenberg, D. S. Bruno, R. M., Sakmann, B., and Helmchen, F. (2007). Spatial organization of neuronal population responses in layer $3 / 3$ of rat barrel cortex J. Neurosci. 27, 13316-13328.

Kim, U., and McCormick, D. A. (1998). The functional influence of burst and tonic firing mode on synaptic interactions in the thalamus. J. Neurosci. 18 9500-9516.

König, N., Hornung, J. P., and Van der Loos, H. (1981). Identification of Cajal-Retzius cells in immature rodent cerebral cortex: a combined Golgi-EM study. Neurosci. Lett. 27, 225-229.

Landgraf, R., and Neumann, I. D. (2004). Vasopressin and oxytocin release within the brain: a dynamic concept of multiple and variable modes of neuropeptide communication. Front Neuroendocrinol. 25, 150-176.

Licino, J., Mastronardi, C., and Wong, M. L. (2007). Pharmacogenomics of neuroimmune interactions in human psychiatric disorders. Exp. Physiol. 92, 807-811.
Lindsten, T., Zong, W. X., and Thompson, C. B. (2005). Defining the role of the $\mathrm{Bcl}-2$ family of proteins in the nervous system. Neuroscientist $11,10-15$.

Liu, L., van Groen, T., Kadish, I., and Tollefsbol, T. O. (2009). DNA methylation impacts on learning and memory in aging. Neurobiol. Aging 30, 549-560.

Louvi, A., Sisodia, S. S., and Grove, E. A. (2004). Presenilin 1 in migration and morphogenesis in the central nervous system. Development 131 , 3093-3105.

Luskin, M. B., and Shatz, C. J. (1985a). Neurogenesis of the cat's primary visual cortex. J. Comp. Neurol. 242, 611-631.

Luskin, M. B., and Shatz, C. J. (1985b). Studies of the earliest generated cells of the cat's visual cortex: cogeneration of subplate and marginal zones. J. Neurosci. 5, 1062-1075.

Mallamaci, A., and Stoykova, A. (2006) Gene networks controlling early cerebral cortex arealization. Eur. J. Neuroscience. 23, 847-856.

Marin-Padilla, M. (1971). Early prenatal ontogenesis of the cerebral cortex (neocortex) of the cat (Felis domestica). A Golgi study. I. The primordial neocortical organization. Z. Anat. Entwicklungsgesch. 134, 117-145.

Marin-Padilla, M. (1978). Dual origin of the mammalian neocortex and evolution of the cortical plate. Anat. Embryol. (Berl.) 152, 109-126.

Marin-Padilla, M., and MarinPadilla, T. M. (1982). Origin, prenatal development and structural organization of layer I of the human cerebral (motor) cortex. A Golgi study. Anat. Embryol. (Berl.) 164, 161-206.

Martin, K. A. (2002). Microcircuits in visual cortex. Curr. Opin. Neurobiol. $12,418-425$.

McClung, C. A., and Nestler, E. J. (2008). Neuroplasticity mediated by altered gene expression. Neuropsychopharmacology 33, 3-17.

McConnell, S. K., Ghosh, A., and Shatz, C. J. (1989). Subplate neurons pioneer the first axon pathway from the cerebral cortex. Science 245, 978-982.

McConnell, S. K., Ghosh, A., and Shatz, C. J. (1994). Subplate pioneers and the formation of descending connections from cerebral cortex. J. Neurosci. 14, 1892-1907.

McQuillen, P. S., Sheldon, R. A., Shatz, C. J., and Ferriero, D. M. (2003). Selective vulnerability of subplate neurons after early neonatal hypoxia-ischemia. J. Neurosci. 23, 3308-3315.

Mehler, M. F., and Mattick, J. S. (2007) Noncoding RNAs and RNA editing 
in brain development, functional diversification, and neurological disease. Physiol. Rev. 87, 799-823.

Molinari, M., Dell'Anna, M.E., Rausell, E., Leggio, M. G., Hashikawa, T., and Jones, E. G. (1995). Auditory thalamocortical pathways defined in monkeys by calcium-binding protein immunoreactivity. J. Comp. Neurol. 362, 171-194.

Nelson, R. J., Trainor, B. C., Chiavegatto, S., and Demas, G. E. (2006). Pleiotropic contributions of nitric oxide to aggressive behavior. Neurosci. Biobehav. Rev. 30, 346-355.

Reep, R. L., and Goodwin, G. S. (1988). Layer 7 of rodent cerebral cortex. Neurosci Lett. 90, 15-20.

Russo, V. C., Gluckman, P. D., Feldman, E. L., and Werther, G. A. (2005). The insulin-like growth factor system and its pleiotropic functions in brain. Endocr. Rev. 26, 916-943.

Rygh, L. J., Suzuki, R., Rahman, W., Wong, Y., Vonsy, J. L., Sandhu, H., Webber, M., Hunt, S., and Dickenson, A. H. (2006). Local and descending circuits regulate long-term potentiation and zif268 expression in spinal neurons. Eur. J. Neurosci. 24, 761-772.

Scharfman, H. E. (2007). The neurobiology of epilepsy. Curr. Neurol. Neurosci. Rep. 7, 348-354.

Schmitzer-Torbert, N., Jackson, J., Henze, D., Harris, K., and Redish, A. D. (2005). Quantitative measures of cluster quality for use in extracellular recordings. Neuroscience 131, 1-11.

Shinoda, Y., Sugihara, I., Wu, H. S., and Sugiuchi, Y. (2000). The entire trajectory of single climbing and mossy fibers in the cerebellar nuclei and cortex. Prog. Brain Res. 124, 173-186.

Stewart, G. R., and Pearlman, A. L. (1987). Fibronectin like immunoreactivity in the developing cerebral cortex. J. Neurosci. 7, 3325-3333.

Takano, T., Akahori, S., and Takeuchi, Y. (2006). Neuronal apoptosis and gray matter heterotopia in microcephaly produced by cytosine arabinoside in mice. Brain Res. 1089, 55-66.

Taniura, H., Sng, J. C., and Yoneda, Y. (2007). Histone modifications in the brain. Neurochem. Int. 51, 85-91.

Tomioka, R., and Rockland, K. S. (2007). Long-distance corticocortical GABAergic neurons in the adult monkey white and gray matter. J. Comp. Neurol. 505, 526-538.

Torres-Reveron, J.E., and Friedlander, M. J. (2005). Quantal Analysis of Synaptic Connections Between Individual Subplate and Cortical Plate Neurons in Rat Visual Cortex. Presented at Society for Neuroscience Annual Meeting, Washington, DC, USA, November 12-16.

Torres-Reveron, J.E., and Friedlander, M. J. (2007). Properties of persistent postnatal cortical subplate neurons. J. Neurosci. 27, 9962-9974.

Ulrich, D., and Huguenard, J. R. (1996). Gamma-aminobutyric acid type B receptor-dependent burst-firing in thalamic neurons: a dynamic clamp study. Proc. Natl. Acad. Sci. U.S.A. 93, 13245-13249.

Uylings, H. B., and Delalle, I. (1997). Morphology of neuropeptide Y-immunoreactive neurons and fibers in human prefrontal cortex during prenatal and postnatal development. J. Comp. Neurol. 379, 523-540.

Valverde, F., Facal-Valverde, M. V., Santacana, M., and Heredia, M. (1989). Development and differentiation of early generated cells of sublayer Vlb in the somatosensory cortex of the rat: a correlated Golgi and autoradiographic study. J. Comp. Neurol. 290, 118-140.

Vandevelde, I. L., Duckworth, E., and Reep, R. L. (1996). Layer 7 and the gray matter trajectories of cortico-cortical axons in rats. Anat. Embryol. (Berl.) 194, 581-593.

Waites, C. L., Craig, A. M., and Garner, C. C. (2005). Mechanisms of vertebrate synaptogenesis. Annu. Rev. Neurosci. 28, 251-274.

Webster, M. J., Herman, M. M., Kleinman, J.E., and Shannon Weickert, C. (2006). BDNF and trkB mRNA expression in the hippocampus and temporal cortex during the human lifespan. Gene Expr. Patterns. 6, 941-951.

Winokur, R. S., Kubal, T., Liu, D. Davis, S. F., and Smith, B. N. (2004). Recurrent excitation in the dentate gyrus of a murine model of temporal lobe epilepsy. Epilepsy Res. 58, 93-105.

Woo, T. U., Beale, J. M., and Finlay, B. L. (1991). Dual fate of subplate neurons in a rodent. Cereb. Cortex 1 , 433-443.

Wood, J. G., Martin, S., and Price, D. J. (1992). Evidence that the earliest generated cells of the murine cerebral cortex form a transient population in the subplate and marginal zone. Brain Res. Dev. Brain Res. 66, 137-140.

Zimmermann, H. (2006). Nucleotide signaling in nervous system development. Pflugers Arch. 452, 573-588.

Conflict of Interest Statement: The authors declare that the research was conducted in the absence of any commercial or financial relationships that could be construed as a potential conflict of interest.

Received: 02 July 2009; paper pending published: 12 July 2009; accepted: 24 July 2009; published online: 07 August 2009. Citation:FriedlanderMJand Torres-Reveron $J$ (2009) The changing roles of neurons in the cortical subplate. Front. Neuroanat. 3:15. doi: 10.3389/neuro.05.015.2009 Copyright (C) 2009 Friedlander and TorresReveron. This is an open-access article subject to an exclusive license agreement between the authors and the Frontiers Research Foundation, which permits unrestricted use, distribution, and reproduction in any medium, provided the original authors and source are credited. 